\title{
How to get the most out of your payment plan membership
}

Did you know that there are many benefits you can take advantage of as soon as you become a member of Simplyhealth Professionals? They're all included! Here is a selection of just some of our member benefits - we are much more than simply a payment plan provider for your practice.

\section{Professional support services}

Our professional support services team, headed up by Head Dental Officer, Catherine Rutland, provides member dentists with advice, guidance and information on a range of issues such as compliance and regulations, complaints, clinical concerns and contractual queries.

Our UKAS accredited Excel programme is a great way of ensuring you are working towards best practice.

You also have access to our 25 strong team of dental practice advisors across the UK. Each one offers a vast amount of experience in general practice, as well as an extraordinary array of individual skills within dentistry.

We have the strongest network of supporting dentists of any dental plan provider.

Guy Ward, Principal Dentist at Mobberley Road Dental Practice, said: 'I love that there's this team of experts behind me ready to provide everything from $C Q C$ inspection preparation to $C P D$ training, marketing advice to budget planning'

\section{Client support}

Customer Service Provider of the Year finalists in the 2018 Dental Industry Awards, we set standards to exceed expectations.

A dedicated team of practice support advisors are there to help and support you with day-to-day issues. This coupled with our customer advisors team handling, on average, around 10,000 calls and nearly 1,300 emails a month from patients, supports you by taking the pressure off your practice team.

Afonso Correia, Associate Dentist at Chapel Dental, said: 'The level of professionalism is outstanding and that makes everything easier. We have regular meetings to check our goals and adjust some things if necessary. We feel supported and taken care of.'

\section{Business development support}

Our business development consultants have a wealth of invaluable business and dental experience. They will work with you and your practice teams, providing business advice.

They can help you set and achieve your goals, and work with you to become more profitable, aiding financial planning and assisting you in exploring new opportunities.

Edmund Gazala, Principal Dentist at Old Mill Dental Surgery, said: 'I cannot find the words to thank you for all your professional support for the last two years. You have been involved in our Denplan support on a constant basis, were accessible all the time (sometimes even on weekends or late evenings) when needed and you have always responded promptly to our enquiries.'

\section{Marketing support}

All members have access to our in-house marketing team and practice marketing consultancy visits. We can provide geo-demographic

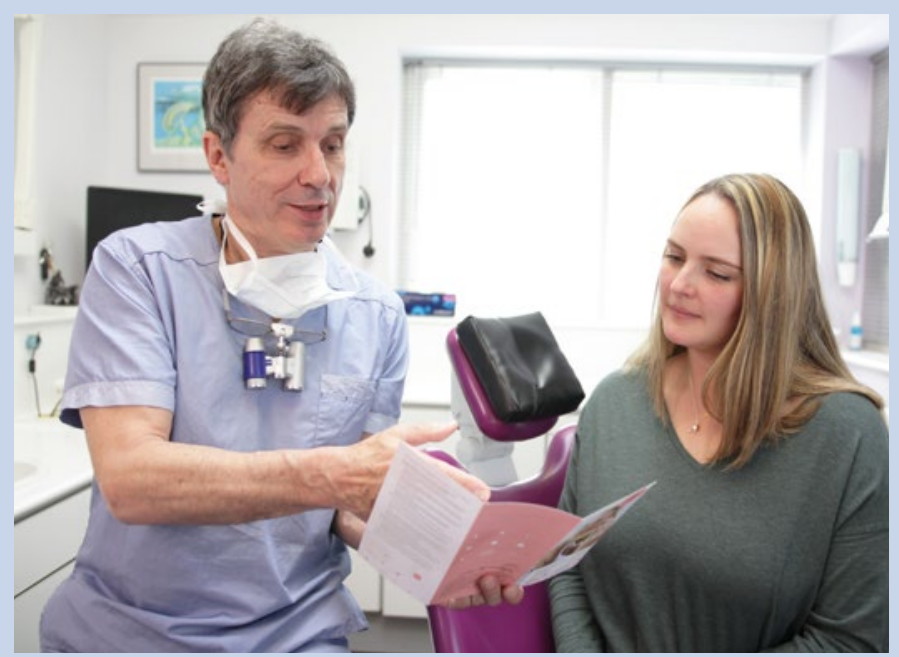

profiling of your patients to give you a greater understanding of who your existing and potential patients are whilst helping you to target, acquire and develop profitable patient relationships.

We can also draw up a marketing plan specific for your practice needs and help you to produce practice-branded literature either by using our free online design service or bespoke materials via our in-house design studio.

Helen Clark, Practice Manager at Paul Lowe Dentistry, said: 'Carina and her design team at Simplyhealth Professionals have played a key role in helping to realise the vision of growth at Paul Lowe Dentistry. We have seen a patient growth increase of $35 \%$ compared to the previous year, this has been achieved through a campaign plan they suggested.'

\section{Tailored training and Events}

Awarded the prestigious BDIA code of practice for all our dental CPD training, The Academy, our in-house training provision, means you'll receive the highest level of training support.

Each year we organise a comprehensive range of events for you and your practice team that will leave you feeling revitalised and ready to head back to the practice with a new perspective.

From essential CPD learning at our Forums and clinical training courses, to our exciting charity challenges and sporting (cycle, ski, golf and hiking) conferences. There is something for the whole practice team to get involved with, whilst taking the opportunity to network and socialise.

Gary Turner, Principal Dentist, White Gables Dental Practice (attended The Forums last year) said: 'I think the balance is just right. It's always great to meet up with other practice owners and share stories, issues and problems over in a relaxed environment.'

Call us today for a free, no obligation consultation on 08001699962 or visit denplan.co.uk/dentists. 